\title{
Extramedullary plasmacytoma of the colon: a rare cause of gastrointestinal bleeding
}
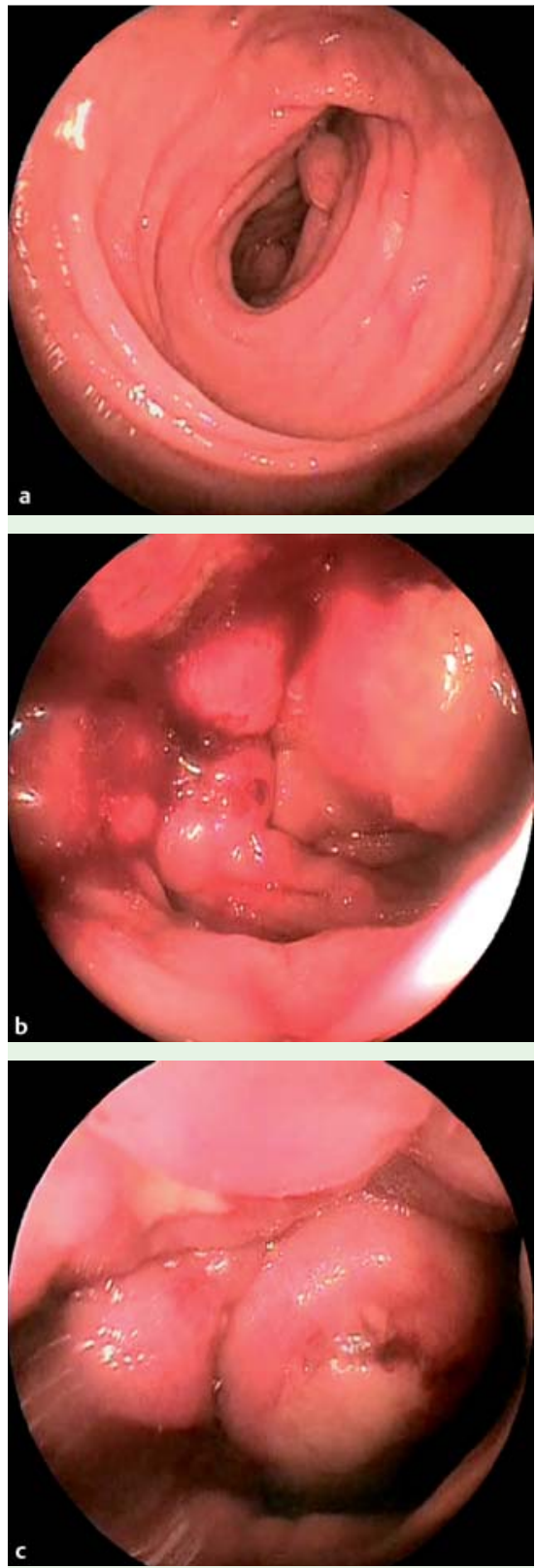

Fig. 1 a The hepatic flexure on colonoscopy. b Extramedullary plasmacytoma of the colon. c Ulcerated mucosa.

A 74-year-old man presented with a 48hour history of diarrhea, abdominal pain, and rectal bleeding. He was known to have multiple myeloma, which had been diagnosed in 2001. Although complete remission was achieved after chemotherapy, the patient had two relapses: a malignant pericardial effusion (2003) and bone marrow relapse (May, 2008). Initial evalu-

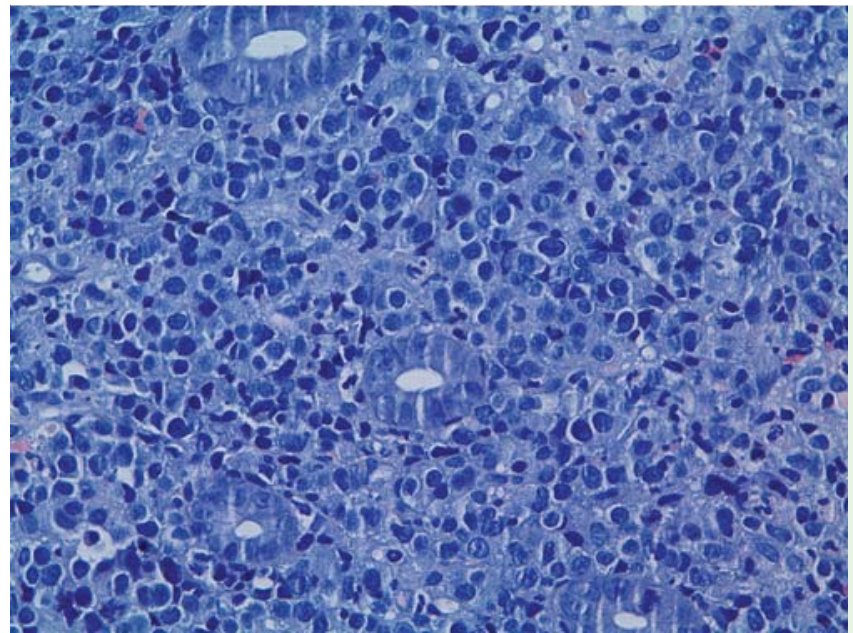

Fig. 2 Histological section showing plasma cells.

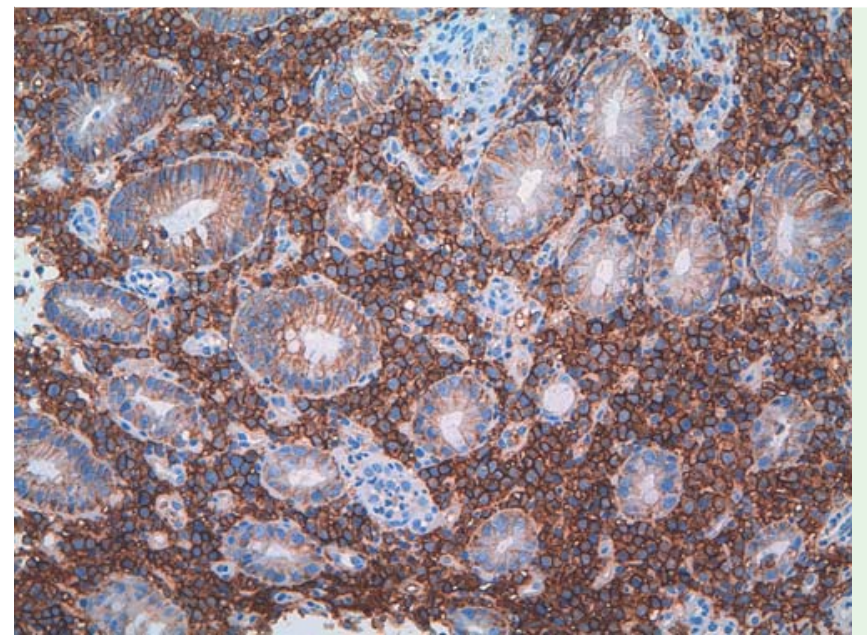

Fig. 3 Immunohistochemical staining positive for CD138.

ation revealed an abdominal mass on the right side, hematochezia, hemoglobin level of $11.4 \mathrm{~g} / \mathrm{dL}$, and abnormal renal function. Urgent colonoscopy disclosed pseudomembranous colitis in the left colon, and the hepatic flexure was stiff. A large number of coalescent intracolonic masses were found, covered in some places by ulcerated mucosa with fibrin ( $\bullet$ Fig. 1).

Right colon stenosis was also seen. Pathological examination showed an atypical plasmacytic cell infiltration of the mucosa (๑ Fig. 2).

Immunohistochemically, these cells showed reactivity for CD138, a marker of viable myeloma cells ( $\bullet$ Fig. 3 ).

Multiple myeloma is a neoplastic proliferation of monoclonal plasma cells, which can result in bone lesions, infections, kidney failure, bone marrow failure, hyper- calcemia, and hyperviscosity syndrome. It is usually confined to the bone marrow. Extramedullary plasmacytomas comprise $4 \%$ of all plasma cells tumors and occur mainly in the upper respiratory tract $(82.2 \%)$; the gastrointestinal tract is involved in only $7.2 \%$ of cases [1]. All segments of the gastrointestinal tract may be involved, but the small bowel is the most common site of infiltration, followed by the stomach, colon, and esophagus. Clinical manifestations are usually nonspecific: anorexia, weight loss, abdominal pain, vomiting, gastrointestinal bleeding, intestinal obstruction, or malabsorption. There have been only a few published reports of the endoscopic features of gastrointestinal plasmacytoma, which usually manifests as ulcers, ulcerated masses, irregular thickened mucosa, or multiple 
polyps [2]. In this report we have presented the endoscopic appearance of this highly unusual tumor. To our knowledge, only 14 cases have been reported so far [3-5].

Endoscopy_UCTN_Code_CCL_1AD_2AC

D. Collado Pacheco, M. Moran Ortiz de Solórzano, E. Quintanilla Lázaro, I. Chico Álvarez, L. R. Rábago Torre

Hospital Universitario Severo Ochoa, Leganés (Madrid), Spain

\section{References}

1 Alexiou C, Kau RJ, Dietzfelbinger $H$ et al. Extramedullary plasmacytoma. Tumor occurrence and therapeutics concepts. Cancer 1999; 85: 240-242

2 Chim CS, Wong WM, Nicholls J et al. Extramedullary sites of involvement in hematologic malignancies. Case 3: Hemorragic gastric plasmacytoma as the primary presentation in multiple myeloma. J Clin Oncol 2002; 20: $344-347$

3 Gupta V, Nahak B, Sakhuja P et al. Primary isolated plasmacytoma of the colon. World J Surg Oncol 2007; 5: 47

4 Doki T, Takeuchi $O$, Kaiho $T$ et al. Primary isolated extramedullary plasmacytoma of the colon. Int J Colorectal Dis 2008; 23: $719-720$

5 Jones JE, Brand MI, Saclarides TJ et al. Primary extramedullary plasmacytomas of the colon. Am Surg 2008; 74: 873-874
Bibliography

DOI $10.1055 / \mathrm{s}-0029-1215225$

Endoscopy 2009; 41: E306-E307

(c) Georg Thieme Verlag KG Stuttgart · New York . ISSN 0013-726X

\section{Corresponding author}

\section{Collado Pacheco}

Hospital Universitario Severo Ochoa

Avda Orellana s/n - 28911

Leganés (Madrid)

Spain

davidcolladopacheco@yahoo.es 